\title{
Trade Effects of the Euro: a Comparison of Estimators
}

\author{
Richard Baldwin \\ Daria Taglioni \\ European Central Bank
}

Graduate Institute of International Studies

\begin{abstract}
This paper provides a minimalist derivation of the gravity equation and uses it to identify three common errors in the literature, what we call the gold, silver and bronze medal errors. The paper provides estimates of the size of the biases taking the currency union trade effect as an example. We argue that the best estimator involves time-varying country dummies, a time dummy and time-invariant pair dummies.
\end{abstract}

- JEL classification: F41

- Keywords: Trade, Euro, Gravity

\section{Introduction}

The gravity model is a workhorse tool in a wide range of empirical fields. It is regularly used to estimate the impact of trade agreements, exchange rate volatility, currency unions, the 'border effect', common or related language usage and it even has a range of more exotic applications such as the impact of religion on trade and the impact of trade on the likelihood of war. Its popularity rests on three pillars: First, international trade flows are a key element in all manner of economic relationships, so there is a demand for knowing what normal trade flows should be. Second, the data necessary to estimate it are now easily accessible to all researchers. Third, a number of high profile papers have established the gravity models respec-

\footnotetext{
*Corresponding address: Richard Balwin, Professor, Graduate Institute of International Studies (HEI), Geneva; European Central Bank

@ $2007-C e n t e r$ for International Economics, Sejong Institution, All Rights Reserved.
} 
tability (e.g. McCallum 1995, Frankel 1997, Rose 2000) and establish a set of standard practices that are used to address the ad hoc empirical choices that face any empirical researcher. Some of these standard practices, in turns out, impart mild to severe biases to the point estimates.

This paper reviews the basic theory behind the gravity equation and uses this to explain why several of the standard choices are incorrect and why they typically bias the results. After exploring these points from a microeconomic and statistical theoretical perspective, we review the actual impact of the errors on a specific database which has been used to examine the trade effects of the euro.

\section{Literature}

The gravity model emerged in the 1960s as an empirical specification with handwaving theoretical underpinnings (Tinbergen 1962, Poyhonen 1963, Linnemann 1966). Leamer and Stern's famous 1970 book provided some foundations (three distinct sets, in fact). The best is based on what could be called the 'potluck assumption.' Nations produce their goods and throw them all into a pot; then each nation draws its consumption out of the pot in proportion to its income. The expected value of nation-i's consumption produced by nation-j will equal the product of nation-i's share of world GDP times nation-j's share of world GDP. In this way, bilateral trade is proportional the product of the GDP shares.

Anderson (1979) seems to be the first to provide clear microfoundations that rely only on assumptions that would strike present-day readers as absolutely standard. The cornerstone of Anderson's theory, however, rested on an assumption that was viewed as ad hoc at the time, namely that each nation produced a unique good that was only imperfectly substitutable with other nations's goods. The gravity model fell into disrepute in the 1970s and 1980s; for example, Alan Deardoff refers to the gravity model as having "somewhat dubious theoretical heritage" (Deardoff 1984 p. 503).

The gravity equation's next set of theoretical foundations came when Bergstrand (1985) sought to provide theoretical foundations based on the old trade theory; in particular he developed a theoretical connection between factor endowments and bilateral trade. He did not manage to reduce the complicated price terms to an empirically implement-able equation; "calculating the complex price terms in [his expression] is beyond this paper's scope," he wrote. He argued that one could approximate the theory-based price terms with various existing price indices. Bergstrand $(1989,1990)$ re-did his earlier effort using the Helpman-Krugman 
model (Helpman and Krugman 1985) that married the new and old trade theory, but he continued to use existing price indices instead of the ones he justifies with his theory (Bergstrand 1989, p. 147). More generally, the emergence of the "new trade theory' in the late 1970s and early 1980s (e.g. Krugman 1979, 1980, 1981, Helpman 1981) started a trend where the gravity model went from having too few theoretical foundations to having too many. More recently, Eaton and Kortum (2002) provide Walrasian microfoundations for the gravity model. For example, in a 1995 paper on the gravity model Deardorff writes: "it is not all that difficult to justify even simple forms of the gravity equation from standard trade theories." Also see Evenett and Keller (2002) for a thorough discussion of this point.

Anderson and Van Wincoop (2001), published as Anderson and Van Wincoop (2003), is a recent well-known effort to microfound the gravity equations. The basic theory in Anderson and Van Wincoop (2001) is very close the Anderson (1979); the main value added is the derivation of a practical way of using the full expenditure system to estimate key parameters on cross-section data. Since this procedure is difficult, they also use an alternative procedure of using of nationdummies - a procedure first employed by Harrigian (1996).

Recent years have seen a number of papers by empirical trade economists that take the theory seriously, but these are typically viewed as contributions to narrow empirical topics - e.g. the size of the border effect, or the magnitude of the elasticity of substation - so the methodological advances in these papers have been generally ignored in the wider literature. Some of the key papers in this line are Harrigan (1996) and Head and Mayer (2000), and Combes, Lafourcade and Mayer (2005). In a similar vein, a number of papers have tackled the question of 'zeros' in the trade matrix, for example, Helpman, Melitz and Rubinstein (2005), and Westerlund and Wilhelmsson (2006). The former uses an sophisticated two step procedure, the later suggests using a Poisson fixed effects estimator; both show that estimates can be severely biased by incorrect treatment of zero trade flows. We do not address the important issue of 'zeros' in our paper since we use a dataset that has none. Our paper is most closely related to the methodological papers of Pakko and Wall (2001).

\section{Basic Gravity Theory: Gravity for Dummies}

The inspiration for the gravity model comes from physics where the law of gravity states that the force of gravity between two objects is proportional to the 
product of the masses of the two objects divided by the square of the distance between them. In symbols:

$$
\underset{\text { gravity }}{\text { force of }}=G \frac{M_{1} M_{2}}{\left(\text { dist }_{12}\right)^{2}}
$$

In trade, we replace the force of gravity with the value of bilateral trade and the masses $M_{1}$ and $M_{2}$ with the trade partners' GDPs (in physics $G$ is the gravitational constant). Strange as it may seem, this fits the data very well; an R-squared of 0.7 on cross-section data is par for the course. Students of trade theory who have characterised international trade with systems of simultaneous equations may find the empirical success of this hyper-simple relationship to be somewhat disconcerting.

Yet despite its goodness-of-fit, this naïve version of the gravity equation can yield severely biased results. To see this point we need to work through a minimalists theory of the gravity equation. This shows that the gravity equation is essentially an expenditure equation with a market-clearing condition imposed. The simple theory also explains why it fits so well. Expenditure equations do explain expenditure patterns rather well and markets generally do clear. The point, however, tells us that the gravity model is not a model in the usual sense - it is the regression of endogenous variables on endogenous variables.

We note immediately that there is nothing new in our theory (see Introduction). If there is any value added in the theory beyond fixing ideas for subsequent sections of our paper, it lies with the simple presentation. ${ }^{2}$

\section{A. A first-pass gravity equation for bilateral trade}

\section{Step 1: The expenditure share identity}

The first step is the expenditure share identity for a single good exported from the 'origin' nation to the 'destination' nation:

$$
p_{o d} x_{o d} \equiv \text { share }_{o d} E_{d}
$$

where $x_{o d}$ is the quantity of bilateral exports of a single variety from nation 'o' to nation 'd' (the 'o' is a mnemonic for 'origin' and ' $d$ ' for 'destination'), pod is the price of the good inside the importing nation also called the 'landed price', i.e. the

\footnotetext{
${ }^{2}$ The theory here is not new; its basic outline follows Anderson and Van Wincoop (2003), but we extend it to allow for panel data; Anderson-Van-Winccop's theory only applies to cross section data.

${ }^{3}$ We do not need to be specific about exactly which good is the numeraire; more on this below.
} 
price of the imported good that is faced by customers in the importing nation; this is measured in terms of the numeraire. ${ }^{3}$ Of course, this makes xodpod the value of the trade flow measured in terms of the numeraire. Ed is the destination nation's expenditure (again measured in terms of the numeraire) on goods that compete with imports, i.e. tradable goods. By definition, shareod is the share of expenditure in nation $\mathrm{d}$ on a typical variety made in nation-o.

\section{Step 2: The expenditure function: shares depend on relative prices}

Microeconomics tells us that expenditure shares depend upon relative prices and income levels, but we postpone consideration of the income elasticity in this firstpass presentation; the expenditure share is assumed to depend only on relative prices. Adopting the CES demand function and assuming that all goods are traded, the imported good's expenditure share is linked to its relative price by:

$$
\text { share }_{o d} \equiv\left(\frac{p_{o d}}{p_{d}}\right)^{1-\sigma}, \quad \text { where } P_{d} \equiv\left(\sum_{k=1}^{R} n_{k}\left(p_{k d}\right)^{1-\sigma}\right)^{1 /(1-\sigma)}, \quad \sigma>1
$$

where $p_{o d} / P_{d}$ is the 'real price' of $p_{o d}$. Also, $P_{d}$ is nation-d's ideal CES price index (assuming all goods are traded), ' $R$ ' is the number of nations from which nation$\mathrm{d}$ buys things (this includes itself), and is the elasticity of substitution among all varieties (all varieties from each nation are assumed to be symmetric for simplicity); $\mathrm{nk}$ is the number of varieties exported from nation $k$. We assume symmetry of varieties by source-nation to avoid introducing a variety index. As always, all prices here are measured in terms of the numéraire (more on choice of numéraire below). Combining (2) and (1) yields product specific import expenditure equation. This could be estimated directly, but researchers often lack good data on the trade prices. We can get around this by putting more structure on the problem.

\section{Step 3: Adding the pass-through equation}

The landed price in nation-d of goods produced in nation-o are linked to the production costs in nation-o, the bilateral mark-up, and the bilateral trade costs via:

$$
p_{o d}=p_{o} \tau_{o d}
$$

where $p_{o}$ is the producer price in nation-o, and $o_{d}$ reflects all trade costs, natural and manmade. This assumes that the price-cost markup is a parameter (as in DixitStiglitz monopolistic competition or perfect competition with Armington goods). 


\section{Step 4: Aggregating across individual goods}

So far we have per-variety exports. To get total bilateral exports from 'o' to 'd', we multiply the expenditure share function by the number of symmetric varieties that nation 'o' has to offer, namely 'no'. Using upper case $\mathrm{V}$ to indicate to total value of trade, $V_{o d} \equiv n_{o} s_{o d} E_{d}$ and:

$$
V_{o d}=n_{o}\left(p_{o} \tau_{o d}\right)^{1-\sigma} \frac{E_{d}}{P_{d}^{1-\sigma}}
$$

Lacking data on the number of varieties no and producer prices po, we compensate by turning to nation-o's general equilibrium condition.

\section{Step 5: Using general equilibrium in the exporting nation to eliminate the nominal price}

The producer price, $p_{o}$, in the exporting nation-o must adjust such that nation-o can sell all its output, either at home or abroad. Expression So far we have pervariety exports. To get total bilateral exports from 'o' to ' $d$ ', we multiply the expenditure share function by the number of symmetric varieties that nation 'o' has to offer, namely 'no'. Using upper case $\mathrm{V}$ to indicate to total value of trade, $V_{\text {od }} \equiv$ $n_{o} s_{o d} E_{d}$ and:

(4) gives us nation-o sales to each market. Summing over all markets, including o's own market, we get total sales of nation-o goods. Assuming markets clear, nation-o's wages and prices must adjust so the nation-o's production of traded goods equals its sales of trade goods. In symbols, this requires.

$$
Y_{o}=\sum_{d=1}^{R} V_{o d}
$$

Where $Y_{o}$ is nation-o's output measured in terms of the numéraire. Relating $V_{o d}$ to underlying variables with So far we have per-variety exports. To get total bilateral exports from 'o' to 'd', we multiply the expenditure share function by the number of symmetric varieties that nation 'o' has to offer, namely 'no'. Using upper case $\mathrm{V}$ to indicate to total value of trade, $V_{o d} \equiv n_{o} s_{o d} E_{d}$ and:

(4), the market clearing condition for nation-o becomes:

$$
Y_{o}=n_{o} p_{o}^{1-\sigma} \sum_{d=1}^{R}\left(\tau_{o d}^{1-\sigma} \frac{E_{d}}{P_{d}^{1-\sigma}}\right)
$$

where the summation is over all markets (including o's own market). Solving this for $n_{o} p_{o}^{1-\sigma}$ : 


$$
n_{o} p_{o}^{1-\sigma}=\frac{Y_{o}}{\Omega_{o}}, \text { where } \Omega_{o} \equiv \sum_{i=1}^{R}\left(\tau_{o i}^{1-\sigma} \frac{E_{i}}{P_{i}^{1-\sigma}}\right)
$$

Here $\Omega_{o}$ measures what is akin to what is called 'market potential' in the economic geography literature (a nation's market potential is often measured by the sum of its trade partners' real GDPs divided by bilateral distance); the capital-omega is a mnemonic for 'openness' since it measures the openness of nation-o's exports to world markets.

\section{Step 6: A first-pass gravity equation}

Substituting (6) into So far we have per-variety exports. To get total bilateral exports from ' $\mathrm{o}$ ' to ' $\mathrm{d}$ ', we multiply the expenditure share function by the number of symmetric varieties that nation 'o' has to offer, namely 'no'. Using upper case V to indicate to total value of trade, $V_{o d} \equiv n_{o} s_{o d} E_{d}$ and:

(4), we get our first-pass gravity equation:

$$
V_{o d}=\tau_{o d}^{1-\sigma}\left(\frac{Y_{o} E_{d}}{\Omega_{o} p_{d}^{1-\sigma}}\right)
$$

Note that all variables are measured in terms of the numéraire. Expression (7) is a microfounded gravity equation. It is identical to Anderson-Van Wincoop's expression (9). ${ }^{4}$ It is not identical to their final expression, (11), since their last step is only valid for cross-section data. See Box 1.

\section{B. The gravity equation and the 'gravitational un-constant'}

Taking the GDP of nation-o as a proxy for its production of traded goods, and nation-d's GDP as a proxy for its expenditure on traded goods, this can be rewritten to look just like the physical law of gravity.

$$
\begin{gathered}
\text { bilateral } \\
\text { trade }
\end{gathered}=G \frac{Y_{1} Y_{2}}{\left(\text { dist }_{12}\right)^{\text {elasticy-1 }}} ; \quad G \equiv \frac{1}{\Omega_{o}} \frac{1}{P_{d}^{1-\text { elasticity }}}
$$

where the Y's are the nations' GDPs and it is assumed that bilateral trade costs depend only upon bilateral distance in order to make the economic gravity equation resemble the physical one as closely as possible. Importantly, $G$ here is not a constant as it is in the physical world; it is a variable that includes all the

${ }^{4}$ Their $\Pi$ is akin to $\Omega$ our and use they use y to indicate expenditure; they also multiply and divide by world income/expenditure once in the expression and once in their definition of $\Pi$. 
bilateral trade costs between nations o and d so it will be different for every pair of trade partners, and it will vary over time. Ignoring the gravitational un-constant is the source of a large number of errors in the gravity equation literature.

\section{Box 1: Applicability of the Anderson and Van Wincoop (2003) is limited to cross-section data}

Anderson-Van-Wincoop do not stop with (7). They do one more simplification. This last step implies an assumption that will be violated in most recent uses of the gravity equation, i.e. those that employ panel data. Of course, there is no mistake in Anderson and Van Wincoop (2003), since they only use crosssection data, but this important caveat is not always recognised in the literature.

Anderson-Van-Wincoop assert that $\Omega_{i}=P_{i}^{1-\sigma}$ for all nations since $\Omega_{i}=P_{i}^{1-\sigma}$ is a solution to the system of equations that define $\Omega$ and $P^{1-\sigma}$. Their point can be seen from the definition of the price index which yields

$$
\Omega_{o}=\sum_{k} \tau_{o k}^{1-} \sigma \frac{Y_{k}}{\Delta_{k}} \quad \Delta_{o}=\sum_{k} \frac{Y_{k}}{\Omega_{k}} \tau_{k o}^{1-\sigma} \quad \forall o=1, \ldots R
$$

By inspection, the two definitions would continue to hold if $\chi \Omega_{i}=\Delta_{i}$, for any $\chi$, as Anderson-Van Wincoop observe in their footnote 12 of the published paper. What this tells us beyond a doubt is that any set of $\Omega$ and $P^{1-\sigma}$ that solves this set of equations must be proportional.

This proportionality is obviously correct and indeed intuitively obvious. Since $\Omega$ measures the openness of the world to a nation's exports and $P_{i}^{1-\sigma}$ measures the openness of a nation to imports from the world, these two will be related when all bilateral trade costs are symmetric. If nation-o finds itself located in a place that has good market access (which makes exporting easy), then it will automatically be in a place where foreign exporters find it easy to sell into nation-o. The authors go beyond proportionality, claiming that the two are actually equal. The text asserts that the point is "easily verified." This is elaborated upon in footnote 12 , which goes on to say that $\chi \Omega_{i}=\Delta_{i}$ and claims that taking $\chi=1$ is 'a particular normalisation.'

Here we show that $\chi=1$ cannot be a solution in general unless trade costs never vary. Since the Anderson Van Wincoop method is used for panel data, we can be sure that trade costs are varying in which case we cannot take $\Omega_{i}=P_{i}^{1-\sigma}$.

The Anderson-Van Wincoop model is difficult to manipulate since it is basically a CES expenditure system with market clearing conditions imposed. There are two basic problems. The first stems from the high dimensionality of the system. For 
example, with just 3 nations there are 3 expenditure equations for each nation as well as the definitions for the three $\Omega$ 's and the three $P$ 's, and the three adding up constraints. Second, even given endowments and trade costs, it is mathematically impossible to solve for prices and the trade pattern with paper and pencil (the problem is non-integer powers). Given this, one cannot directly demonstrate that $\chi \neq 1$ by finding $\chi$ and showing it is not unity. Instead, we offer a counter example which disproves the general rule and explains why Anderson and Van Wincoop's fourth step is correct for cross-section applications of their equation but incorrect for panel-data applications.

If $\chi=1$ is the solution, then it must work for all cases, including a simple one. What we do here is show that $\chi=1$ cannot be the general solution in the simplest possible case - namely, 3 identical nations with a single factor of production, and bilateral trade costs that are identical for every trade flow. In this case, the definition of $\Omega$ is (symmetry of nations allows us to drop subscripts):

$$
\Omega=\frac{Y}{p^{1-\sigma}}\left(1+2 \tau^{1-\sigma}\right) \leftrightarrow \Omega=\sqrt{Y\left(1+2 \tau^{1-\sigma}\right)}
$$

where the second expression follows by imposing $\Omega=P^{1-\sigma}$.

The problem is that this is inconsistent with a typical nation's market clearing condition. To make the point as simply as possible, we assume, as in Anderson and Van Wincoop (2003), that nations make a single good under conditions of perfect competition and constant returns; we also assume that nations are endowed with a single factor of production, $\mathrm{L}$. Thus the typical nation's income is $Y=w L$ where w is the typical nation's wage and from perfect competition the price of its good is $p=w a$, where ' $a$ ' is the unit labour input coefficient.

Using perfect-competition pricing namely $p=w a$, the definition of income $Y=w L$, and (9), the market clearing condition for the typical nation, namely $p^{1-\sigma}$ $=Y / \Omega$ can be written as:

$$
(w a)^{1-\sigma}=\frac{w L}{\sqrt{w L\left(\left(1+2 \tau^{1-\sigma}\right)\right)}}
$$

The key point in the counter example is that if we take labour as numeraire, so $w=1$, then this holds but only if we choose to measure units of labour in a way such that 'a' exactly equates the left-hand side to the right-hand side. More to the point, once we chose units for labour, then this will only hold if there is no change in bilateral trade costs and no change in GDPs. The same point holds if one takes 
the typical goods price, p, as the numeraire. We have worked out more general examples numerically (using Maple) and we always find that the $\Omega$ and $P^{1-\sigma}$ are proportional regardless of the GDPs and bilateral trade costs, but the factor of proportionality depends upon GDP's and trade costs.

This shows that setting $\Omega=P^{1-\sigma}$ does indeed involve 'a particular normalisation' but we need a different normalisation for every set of GDPs and trade costs. In other words, $\Omega$ does not equal $P^{1-\sigma}$ in data that have a time dimension in them.

\section{Basic Econometric Biases: The Medals}

A large fraction of the gravity model studies contain serious errors, some of which have been repeated so often that they have become accepted practice even though some of them are well recognized by researchers specializing gravity model estimation.

\section{A. Common empirical implementation of the gravity equation}

Empirically implementing (7) requires a number of additional choices. Many of these choices became common practice since Jeffery Frankel's well-known use of the gravity equation in the 1990s, e.g. Frankel (1997). To provide a concrete example, we use a highly cited paper, Rose (2000).

Trade flow choices: For the independent variable, the average bilateral trade flow is used. Specifically exports of France to Germany are averaged with the exports of Germany to France. ${ }^{5}$ Since the economic mass variables are in terms of base-year dollars, the trade flows are deflated by the base year using the US's price index.

Economic mass variable choices: Expenditure on tradable goods, namely Ed, and output of tradable goods, namely Yo are measured with the real GDP figures. The specific data series used are the real GDPs adjusted for local price differences (Penn World Table figures). Since the averaging of bilateral trade flows makes it impossible to know which nation is the origin and which is the destination, it is not possible to separately estimate the coefficients on the origin and destination GDP variables. ${ }^{6}$ The common solution is to work with the product of two nations' GDPs.

\footnotetext{
${ }^{5}$ Since trade flows are observed as exports by the origin nation and imports by the destination flow, most trade flows have to be statistically independent observa- tions. Given that France both imports from and exports to Germany, this implies that typically four values are averaged to get bilateral trade.

${ }^{6}$ Estimating them separately is possible, but rarely rewarding. The point estimates often jump around even though their sum is fairly constant since the exact estimates depend upon the ordering of the data set.
} 
Bilateral trade costs: There is a long tradition in the gravity literature of modelling as depending upon natural barriers (bilateral distance, adjacency, land border, etc.), various measures of manmade trade costs (free trade agreements, etc.), and cultural barriers (common language, religion, etc.). The original contribution of Rose (2000) is to add a common currency dummy to the list. Thus, Rose (2000)'s preferred regression estimates (simplifying for clarity's sake):

$$
\frac{V_{o d}}{P_{U S A}}=\tau_{o d}^{1-\sigma}\left(\frac{G D P_{o}}{P_{o}^{g d p}} \times \frac{G D P_{d}}{P_{d}^{g d p}}\right) ; \quad \tau_{o d}=f\left(\text { dist }_{o d}, \text { other stuff }\right)
$$

where dist $_{\text {od }}$ is the distance between o and $\mathrm{d}, P_{U S A}$ is the US price index and the $P^{g d p}$ 's are the nation-specific GDP deflators.

Now if one estimates (10) when the theory tells you (7) is the true model, the estimates will be marked by omitted variable biases. In particular, the 'gravitational un-constant' (i.e. what Anderson-Van-Wincoop call the multilateral trade resistance, or Frankel-Wei call 'remote-ness') will be in regression residual. What is wrong with this? One big problem - the gold medal of classic gravity model mistakes and one small problem - the bronze medal winner in the mistake race.

- The big problem is that the omitted terms are correlated with the trade-cost term, since $\tau_{o d}$ enters $\Omega_{o}$ and $P_{d}$ directly (see (2) and (6)). This correlation biases the estimate of trade costs and all its determinants including, the currency union dummy.

- The small problem - what might be called the bronze-medal mistake - is the inappropriate deflation of nominal trade values by the US aggregate price index. Since there are global trends in inflation rates, inclusion of this term probably creates biases via spurious correlations. Fortunately, Rose (2000) and other papers offset this error by including time dummies. Since every bilateral trade flow is divided by the same price index, a time dummy corrects the mistaken deflation procedure.

Note that when Glick and Rose (2001) run their regression without the time dummies, their estimated coefficient on the CU dummy is one standard deviation larger than it is with time dummies, so it can be important to correct the small problem. We present more direct evidence on this below.

\section{B. Gold medal error}

To make the point more formally, we turn once more to the first-pass version of the gravity equation. The true model implies that Rose (2000) is estimating: 


$$
\frac{V_{o d}}{P_{U S A}}=\tau_{o d}^{1-} \sigma\left(\frac{G D P_{o}}{P_{o}^{g d p}} \times \frac{G D P_{d}}{P_{d}^{g d p}}\right)\left\{\frac{P_{d}^{g d p}}{P_{d}^{1-\sigma}} \frac{P_{o}^{g d p}}{\Omega_{o}} \frac{1}{P_{U S A}}\right\} ; \quad \tau_{o d}=f\left(\text { dist }_{\text {od }}, \text { other stuff }\right)
$$

Here and subsequently, assume that the bronze-medal mistake - deflation by US price index - has been offset by time dummies so we can ignore $P_{U S A}$. Again simplifying for the sake of illustration, suppose the true model of bilateral trade costs is:

$$
\tau_{\text {od }}=D I S T_{\text {od }}^{b_{1}} \exp \left[C U_{o d, t}\right]^{-b_{2}} Z_{o d, t}^{b_{3}} ; \quad b_{1}, b_{2}>0
$$

where $C U$ is the currency union dummy and $Z$ is the other (omitted) determinants of bilateral trade costs (suppose there is only one for simplicity's sake). Then the true gravity model (in $\operatorname{logs}$ ) is:

$$
y=X_{i} \beta_{1}+X_{2} \beta_{2}+\varepsilon
$$

where $y$ is the trade flow, $X_{1}$ includes the product of the real GDP's, bilateral distance and the $C U$ dummy, and $X_{2}$ includes the 'gravitational-unconstant' terms, $P$ and $\Omega$, as well as that omitted determinants of trade costs $Z$. Omitting $X_{2}$ is like testing for the partial effects of the observed regressors holding fixed the unobservable un-constant term.

Thus what Rose (2000) was estimating was:

$$
y=\beta_{0}+X_{1} \beta_{1}+u_{t}
$$

where the error $u$ consists of two parts, i.e. $u=\varepsilon+\gamma q$. Under the OLS version of true gravity model, $\varepsilon$ is the zero-mean error of the regression and is uncorrelated with any of the regressors. By normalisation, the omitted term $q$ also has zero mean. Thus $E(u)=0$ is also true. However since we demonstrated that $q$ is correlated with regressors in $X_{1}$, then so is $u$, and we have an endogeneity problem.

It is easy to calculate the bias determined by omitting the un-constant term, by writing its linear projection onto the observable explanatory variables (Wooldridge 2002):

$$
q=\delta_{0}+\delta_{1} x_{1}+\delta_{2} x_{2}+\ldots+\delta_{k} x_{k}+r
$$

where, by definition of linear projection, $E(r)=0, \operatorname{Cov}\left(x j^{\prime} r\right)=0, j=1,2, \ldots, k$. Plugging $q$ into the Rose (2000) specification reported above, we can easily derive the 'omitted variables bias' on OLS regressors in $X_{1}$ as:

$$
p \lim \hat{\beta}_{j}=\beta_{j}+\gamma \delta_{j}
$$


with $\hat{\delta}_{j}=x \operatorname{Cov}\left({ }_{k}, q\right) / \operatorname{Var}\left(x_{k}\right)$. This formula allows us to determine easily the sign and magnitude of the bias in the estimators. If the omitted un-constant term is likely to have a positive effect on trade, i.e. $\gamma>0$ and it is positively correlated with the other regressors, i.e. $\operatorname{Corr}(x k, q)>0$, then for the formula above, their effect is likely to be overestimated (this is confirmed in our regression results below).

\section{Bias on the 'economic mass variable'}

Another result of ignoring the 'gravitational un-constant' is a measurement error in the economic mass variable. To see this, consider the GDP terms used in Rose (2000) as 'noisy versions of the true size variables' in the gravity equation specified in (7). Let suppose that in the relationship:

$$
y=x_{1} \beta_{1}+\varepsilon_{t}
$$

where $x_{1}$ is equal to $\left(G D P_{o} \underline{G D P_{d}} / P_{o}{ }^{g d p} P_{d}{ }^{g d p}\right)$ and is the noisy version of the true variable $x_{1}{ }^{*}$ equal to $\left(G D P_{o} G D P_{d} / \Omega_{o} P_{d}{ }^{1-\sigma}\right)$. Let assume further that the true model is:

$$
y^{*}=x_{1}^{*} \beta_{1}+\varepsilon_{t}
$$

where $E x^{*} \varepsilon=0$, with the star denoting the true values of the underlying variables and let's suppose that the relationship $x_{1}=x_{1}{ }^{*}+u$ holds. Finally, for simplicity's sake assume that the measurement error is unbiased and uncorrelated with the disturbances in the true equation.

Substituting the above relationship into the true regression we obtain.

$$
y^{*}=x_{1} \beta_{1}+\varepsilon_{t}-u \beta_{1}
$$

This implies that $\eta=\varepsilon-\beta u$ is not orthogonal to the mismeasured independent variable $x_{1}$. To see this note that the above assumptions require

$$
E\left(x_{1}^{\prime} \eta\right)=E\left[x_{1}^{\prime}(\varepsilon-\beta u)\right]=-\beta \sigma_{u}^{2}
$$

This negative covariance between $x$ and entails that the OLS estimator of $\beta$ is asymptotically downward biased when there are errors in measuring the independent $x$ variables. Indeed we have:

$$
\hat{\beta}=\frac{\frac{1}{N} \sum_{i=1}^{N}\left(x_{i}^{*}+u_{i}\right)\left(\beta x_{i}^{*}+\varepsilon_{i}\right)}{\frac{1}{N} \sum_{i=1}^{N}\left(x_{i}^{*}+u_{i}\right)^{2}} \rightarrow \frac{\beta E\left(x^{* 2}\right)}{E\left(x^{* 2}\right)+\sigma_{u}^{2}}<\beta
$$


Below, we confirm the downward bias of the 'economic mass' variables in the mispecified gravity equation in our empirical testing in Section 4.

\section{The currency union dummy coefficient is biased: Part 1}

We can be absolutely sure that the currency union dummy, $C U$, and $x_{21}$ are correlated since $x_{21}$ contains $C U$ and all other determinants of bilateral trade costs. In short, omission of the relative-price-matters term produces biased results. But what is the likely direction of the bias? As shown above, it depends on the sign of and on the sign of the correlation between $C U$ and $X_{21}$.

Stepping outside the model for a moment, suppose that not all goods are traded, so the GDP price deflators include non-traded goods prices. Since the $P$ and include only traded goods prices, $x_{21}$ is proportional to the ratio of non-traded prices to traded prices in the trading nations. If non-traded goods are idiosyncratically high in these nations, they will be idiosyncratically open (consumers substitute away from nontraded goods). Next, suppose that nations that are idiosyncratically open are more likely to engage in pro-trade policies, like a currency union or FTA. If both of these conjectures are true, there will be a positive correlation between $C U$ and the relative-prices-matter term. In this case, the coefficient on the $C U$ dummy is upward biased.

As a matter of fact, most estimates of the Rose effect that ignore the relativeprices-matter term estimate the pro-trade effects of a currency union to be amazingly high. For instance in Rose's preferred regression, the estimated currencyunion effect is 1.21 (see Rose 2000 Table 2 column labelled 'pooled'). In the same paper, he partially corrects for the gold medal mistake by doing difference-indifference estimation and estimates the currency-union effect to be 0.16 (see unnumbered equation Rose 2000 p. 28). ${ }^{7}$ The first (with the gold medal mistake) implies the currency union effect boosts trade by $235 \%$. The second with the mistake partially corrected, it is $17 \%{ }^{8}$

\section{The currency union dummy coefficient is biased: Part 2}

A second bias in the CU dummy estimator stems from omitted determinants of

\footnotetext{
${ }^{7}$ As explained below, this diff-in-diff is like including pair dummies and this removes the cross-section correlation between $x_{z 1}$ and $C U$.

${ }^{8}$ Since the estimation is in $\operatorname{logs}$, the trade effect in percentages is $\exp \{b\}-1$, where $b$ is the estimated coefficient on the binary dummy.
} 
bilateral trade costs. Bilateral trade costs are determined by many factors, ranging from personal relationships among business leaders that were developed as school children on cultural exchange programmes to convenient flight schedules. David Hummels has a series of papers pushing forward the range of these factors that can be measured, but there will always be omitted variables in the regression. This is not a problem unless the omitted variables are correlated with $X_{1}$ variables. The key to the biases, however, it is very likely that the omitted pro-bilateral trade variables are positively correlated with the 'variable of interest', i.e. the $C U$ dummy in this case. The point is that the formation of currency unions is not random but rather driven by many factors, including many of the factors omitted from the gravity regression.

If the omitted variables and $C U$ are positively correlated, the estimated trade impact will be upward biased for this second independent reason. The size of this bias is quite difficult to judge since it stems from factors that are unobservable to the econometrician.

\section{Nuisances with nuisance variables}

Many researchers have found that the 'nuisance' variables in the gravity model (the coefficients on economics mass and distance) are indeed a huge nuisance. The simplest theory that relies on homothetic in tastes and economic structure tells us the GDP variables should have coefficients of unity, and while slightly more sophisticated theory explains why the elastiticites may deviate from unity, most people get suspicious when the point estimates on GDP fall below, say 0.5. It is plain from the reasoning above that we should expect the GDP elastiticites to be biased downward, since $x_{21}$ contains the price index that is used to deflate nominal GDP. The correlation is not -1 , however, since $z_{21}$ includes the $P$ and terms as well. Since the ratio of traded to nontraded goods will vary across country samples and time periods, the biases on the GDP coefficient need not be systematic. Moreover, GDPs are merely a proxy for the correct variables, namely expenditure on tradable goods for the destination nation and production of tradable goods for the origin nation. They tells us that the usual measurement errors will tend to bias the economic mass coefficients towards zero.

\section{Examples from the literature}

We can see many examples in the literature of just how large the gold-medal mistake can be. Rose (2000) reports that the currency union trade effect is $+235 \%$, while using pair fixed effects on his original dataset, Rose (2001) shows that correc- 
ting for the gold-medal mistake makes the currency-union effect disappear. Specifically, when he includes pair dummies, the raw estimate on the $C U$ dummy is -0.38 and the standard error is 0.67, compared 1.21 in Rose (2000). Glick and Rose (2001) use a massive dataset that includes annual data from 1948 to 1997 data on bilateral trade between 217 countries. Theoretically, that's 50(2172)/2=2,354,450 data points, but with missing observations and zero flows, the dataset has 219,558 observations. When the gold-medal mistake is committed, i.e. the naïve gravity model specification is run on the pooled data, the point estimate on the currency-union effect is 1.30 with a standard error of 0.13 ; when the gold-medal mistake is partially corrected by pair dummies, it drops about 5 standard deviations to 0.65 . When Micco, Stein and Ordoñez (2003 Table 1) estimate the size of the Eurzone's trade impact on developed nation data, they find that the coefficient is 0.198 on pooled data (i.e. with the gold medal mistake), while it is 0.039 when pair dummies are included (a drop of 4 standard errors).

In the next section we discuss various ways of correcting the gold-medal mistake, but before getting there we highlight what is probably the most common error in the gravity literature, what we call the 'silver medal' mistake.

\section{Silver medal mistake}

The basic theory tells us that the gravity equation is a modified expenditure function; it explains the value of spending by one nation on the goods produced by another nation. That is to say, the gravity equation explains uni-directional bilateral trade. Most gravity models, however, are not estimated on uni-directional trade, for example French exports to Germany. Rather, they work with the average of the twoway exports, for example the average of French exports to Germany and German exports to France. There is nothing intrinsically wrong with this, but since it was done without reference to theory, most researchers mistake the log of the average for the average of the logs.

Since gravity theory is so easy, it is trivial to check what the theory tells us about working with average trade flows. Multiplying the left and right hand sides of (7) by the isomorphic expression for $V_{d o}$ and taking the geometric average, we get (dropping the time subscripts for notational convenience):

$$
\begin{aligned}
& \sqrt{V_{o d} V_{d o}}=\frac{\sqrt{\tau_{o d}^{1-\sigma} \tau_{d o}^{1-\sigma}}}{\sqrt{\Omega_{o} P_{o}^{1-\sigma} P_{d}^{1-\sigma} \Omega_{d}}} Y_{o} E_{d} \\
& \Leftrightarrow \frac{\ln V_{o d}+\ln V_{d o}}{2}=(1-\sigma) \ln \tau_{o d}^{a v g}+\ln Y_{o} E_{d}+D_{o t}+D_{d t}
\end{aligned}
$$


Table 1. Data sources and manipulations

\begin{tabular}{|c|c|c|c|}
\hline $\begin{array}{l}\text { Variable } \\
\text { name }\end{array}$ & $\begin{array}{l}\text { Plain language } \\
\text { definition }\end{array}$ & Exact definition & Source \& units \\
\hline $\mathrm{v}_{\mathrm{od}}$ & $\begin{array}{l}\text { Value of exports from } \\
\text { o to d }\end{array}$ & $\begin{array}{l}\text { For most nations there are } 2 \text { observations for bilateral exports, one } \\
\text { from the exporting nation's statistics and one from the importing } \\
\text { nation's statistics. }\end{array}$ & $\begin{array}{l}\text { IMF DOTS; } \\
\text { units: current USD }\end{array}$ \\
\hline $\mathrm{m}_{\text {od }}$ & $\begin{array}{l}\text { Value of imports by } \\
\text { d from } o \text {. }\end{array}$ & $\begin{array}{l}\text { For most nations there are } 2 \text { observations for bilateral imports, one } \\
\text { from the exporting nation's statistics and one from the importing } \\
\text { nation's statistics; 'm' denotes the value of imports. }\end{array}$ & $\begin{array}{l}\text { IMF DOTS; } \\
\text { units: current USD }\end{array}$ \\
\hline lv_avg & $\begin{array}{l}\text { Wrongly averaged } \\
\text { bilateral trade } \\
\text { (silver mistake) }\end{array}$ & $\begin{array}{l}\ln \left\{\left(v_{o d}+v_{d o}+m_{o d}+m_{d o}\right) / 4\right\} \\
\text { As noted above, usually there are } 4 \text { data series for bilateral trade; } \\
\text { exports from } o \text { to } d \text { measured by nation-o and nation-d, and exports } \\
\text { from } d \text { to } o \text { measured by nation-o and nation-d. }\end{array}$ & $\begin{array}{l}\text { authors' calculations; } \\
\text { units: current USD }\end{array}$ \\
\hline lvus_avg & $\begin{array}{l}\text { Wrongly averaged bilateral } \\
\text { trade; wrongly deflated by } \\
\text { US price index } \\
\text { (silver \& bronze mistake) }\end{array}$ & $\begin{array}{l}\ln \{1 / \text { cpi_us }\}+1 v \_ \text {avg } \\
\text { Following common practice in the literature, this deflates the current } \\
\text { dollar price value of trade by a US price index. }\end{array}$ & $\begin{array}{l}\text { OECD for US price index } \\
\text { (CPI); authors' calculations; } \\
\text { units: USD adjusted for US } \\
\text { domestic inflation. }\end{array}$ \\
\hline lv_prd & $\begin{array}{l}\text { Correctly averaged value } \\
\text { of bilateral trade. }\end{array}$ & $\ln \left\{\left(v_{o d} \cdot v_{d o} \cdot m_{o d} \cdot m_{d o}\right)^{(1 / 4)}\right\}$ & $\begin{array}{l}\text { authors' calculations; } \\
\text { Units: current USD }\end{array}$ \\
\hline Lry & $\begin{array}{l}\text { Log of the product of real } \\
\text { GDP. }\end{array}$ & $\frac{e_{n c / \$} G D P_{o}^{n c_{o}}}{P_{o}^{g d p}} \times \frac{e_{n c / \$} G D P_{o}^{n c_{o}}}{P_{o}^{g d p}}$ & IMF; units: current USD. \\
\hline $\mathrm{Ld}$ & log of bilateral distance. & Geodesic (great circle) distance between capitals, & CEPII; units: kilometres \\
\hline
\end{tabular}


where the superscript 'avg' on the bilateral trade costs indicates the geometric average of $\tau_{o d}$ and $\tau_{d o}$. The key point here is that the theory tells us that the averaging should be done after taking logs, not before. Most researchers make the simple mistake of taking the log of the average of uni-directional flows rather than the average of the logs. Specifically, these authors estimate (simplifying to make the point):

$$
\frac{V_{o d}+V_{d o}}{2}=\tau_{o d}^{1-\sigma}\left(\frac{G D P_{o}}{P_{o}^{g d p}} \times \frac{G D P_{d}}{P_{d}^{g d p}}\right)
$$

This can seriously bias the results.

The sum of the logs is approximately the log of the sums, but the approximation gets worse as the two flows to be summed diverge. Defining $\delta$ as the ratio of the bilateral trade flows, i.e. $V_{o d}=\delta V_{o d}$, the log of the sums $\ln \left[\left(V_{o d}+V_{o d}\right) / 2\right]$ is equal to $\ln V_{o d}+\ln (1+\delta)-\ln 2$. The proper way of averaging yields, namely $(1 / 2) \ln \left(V_{o d} V_{o d}\right)$, gives a different answer $\left(\ln \left(V_{o d}\right)+\ln (\delta)\right) / 2$. The wrong way minus the right way gives us the error as:

$$
\text { error }=\ln (1+\delta)+\frac{\ln \delta}{2}-\ln 2, \quad \delta>1
$$

In plain English, the error will not be too bad for nations that have bilaterally balanced trade - in which case is close to unity - but it can be truly horrendous for nations with very unbalanced trade. In the real world, bilaterally unbalanced trade is a huge issue especially for North-South trade flows.

Note that this error is always positive, in other words the silver medal mistake means that researchers are working with overestimates of the bilateral trade. Since this error ends up in the residual, it will bias the point estimates if the error is correlated with included variables. In other words, if the error was evenly or randomly distributed, the silver medal mistake would have little effect. However, if bilateral trade tends to be systematically large for nations that are engaging in the trade policy under study, then the results can be biased. For example, one might conjecture that nations that share a common currency can run larger bilateral deficits in goods trade than other nations and in this case, the silver medal error results in an overestimate of the trade effects of currency unions (we confirm this on real data below).

Turning to the extra biases imparted by the silver medal mistake, we have that the true gravity model (in logs) is $y=\beta_{0}+X_{1} \beta_{1}+X_{2} \beta_{2}+\varepsilon$ where $y, X_{1}$ and $X_{2}$ are defined as above. But what authors using the $\log$ of the sums are estimating is 
$\tilde{y}=X_{1} \beta_{1}+X_{2} \beta_{2}+u_{t}$, where $\tilde{y}$ is the incorrectly averaged bilateral trade flow, which is related to the true measure by $\tilde{y}=y+(\mathrm{I} \delta)$, where is the vector of errors and $I$ is the identity matrix. If the measurement error will have mean different from zero, it will affect estimation of the intercept $\beta_{0}$. More important is the relationship between the measurement error and the explanatory variables. If the measurement error in $y$ is systematically related to one or more explanatory variables in the model, then the OLS estimator (of the variable to which is related) will be biased and possibly inconsistent. The OLS estimate of this will be:

$$
\hat{\beta}_{1}=\beta_{1}+E\left\{X_{1}^{\prime} X_{1}\right\}^{-1} E\left\{X_{1}^{\prime}\left(\beta X_{2}+\mathrm{I} \delta\right)\right\}
$$

In short, the silver medal mistake will always result in a larger error variance than when the dependent variable is measured without error. Furthermore, it will introduce a new source of bias to the extent that the bilateral trade imbalance is correlated with included variables.

Since gravity model theory is so easy, we can also check what authors committing the silver medal mistake are actually estimating when they take the arithmetic average of trade rather than the geometric average. Using (7) for expenditure by nation-d on nation-o's goods and adding this to the obverse, we get:

$$
V_{o d}+V_{o d}=\tau_{o d}^{1-\sigma} \frac{Y_{o} E_{d}}{\Omega_{o} P_{d}^{1-\sigma}}+\tau_{d o} \frac{Y_{d} E_{o}}{\Omega_{d} P_{o}^{1-\sigma}}
$$

Using GDP as proxies for $E$ and $Y$ as usual and gathering terms, this can be written as:

$$
V_{o d}+V_{o d}=\left(\frac{\tau_{o d}^{1-\sigma}}{\Omega_{o} P_{d}^{1-\sigma}}+\frac{\tau_{d o}^{1-\sigma}}{\Omega_{d} P_{o}^{1-\sigma}}\right) G D P_{o} G D P_{d}
$$

Cross-section data. If one uses only cross-section data, then one can use the Anderson-Van-Wincoop trick of choosing units such that $\Omega_{0}=P_{o}^{1-\sigma}$, and the denominators in the right-hand sum are identical. Thus with cross-section data, the use of nation dummies will remove much of the silver mistake. The only thing to note is that the estimates refer to the arithmetic average of bilateral trade costs raised to the $1-\sigma$. To see what this implies, suppose $\tau_{o d}=D I S T_{o d}^{b_{1}} \exp \left[C U_{o d}\right]^{-b_{2}} Z_{o d}^{b_{3}}$ as before, so $\tau_{o d}^{1-\sigma}+\tau_{d o}^{1-\sigma}$ equals $\left(D I S T^{b_{1}} \exp [C U]^{-b_{2}}\right)^{1-\sigma}\left(Z_{o d}^{b_{2}}+Z_{d o}^{b_{2}}\right)$. Following our usual reasoning, the sum of the Z's will end up in the residual and will bias the estimate of $b_{2}$ in the usual fashion. What all this says is that on cross-section data, 
the silver medal mistake is not so bad.

Panel data. If one uses panel data, however, the problem is more severe. The fact that $\Omega_{o} \neq P_{o}^{1-\sigma}$ for most years will mean that the complex sum of the unidirection trade costs will end up in the residuals and thus bias the coefficients on the included variables as discussed above.

\section{Dummies for Gravity Equations}

While the bronze and silver medals have not been widely appreciated in the literature, the gold medal error is now widely recognized and several standard 'fixes' are used to avoid it. The most common are:

- Nation dummies, i.e. a dummy that is one for all trade flows that involves a particular nation. The number of dummies is $\mathrm{R}$.

- Pair dummies, i.e. a dummy that is one for all observations of trade between a given pair of nations. In a typical gravity model estimation this is just the classic fixed effects estimator since the panel is made of time series for every pair's trade. The number of dummies is $\mathrm{R}(\mathrm{R}-1) / 2$, if one has a balanced panel of $\mathrm{R}$ nations and is using averaged bilateral trade data.

This section considers the extent to which these redress the problems. We first look at the theory and then turn to some estimation results that allow us to compare the various approaches in a particular dataset.

\section{A. Some theory}

The simplicity of the gravity model's theoretical foundations allows us to see how the nation and pair dummy fixes affect the biases from a theoretical perspective.

\section{Nation dummies (time invariant)}

Working with uni-directional trade flows to keep the notation simple. The true model can be written as:

$$
V_{o d}=\frac{\tau_{o d}^{1-\sigma}}{\Omega_{o} P_{d}^{1-\sigma}} Y_{o} E_{d} \Leftrightarrow \ln V_{o d, t}=(1-\sigma) \ln \tau_{o d, t}+\ln Y_{o, t} E_{d, t}-\ln \Omega_{o, t}-\ln \left(P_{o, t}^{1-\sigma}\right)
$$

where the D's are nation dummies, and the t's are time sub-scripts; as before we assume $\tau_{o d}=D I S T_{o d}^{b_{1}} \exp \left[C U_{o d, t}\right]^{-b_{2}} Z_{t}^{b_{3}}$. Now if $\Omega$ and $P$ are time-invariant - for example, if one is working with cross-sectional data, nation dummies will remove all the gold medal bias that is due to the fact that $\Omega$ and $P$ include all measures of 
bilateral trade costs. In this case, the true model would be:

$$
\ln V_{o d}=b_{1}(1-\sigma) d i s t_{o d}+b_{2}(1-\sigma) C U_{o d}+\ln Y_{o} E_{d}+b_{3} D_{o}+b_{4} D_{d}
$$

Where, as usual, lower-case variables are the log of their upper-case equivalent.

To see what is going on, it is useful to think of the regression as being done in two steps. First the left-hand side (LHS) variable is regressed on the time-invariant country dummies and then the residuals from that regression are regressed on the three other RHS variables, distance, the currency union dummy, CU, and the joint real GDP variable. For cross-section data, the time-invariant country-specific dummies will completely strip out the gravitational un-constant term in the first stage. However, this does not remove the bias in the CU coefficient stemming from the omitted determinants of bilateral trade.

\section{Panel data implications}

Most recent gravity model estimations use panel data rather than cross section data. Since time-invariant nation dummies only remove part of the cross-section bias but not the time-series bias, country dummies are not enough in panel data. The point is that the omitted terms and $\mathrm{P}$ reflect factors that vary every year. If the researcher ignores this point and include time-invariant country dummies (as is common practice) then only part of the bias is eliminated. Quite specifically, $C U$ varies over time, and assuming that $C U$ affects bilateral trade costs, then its inclusion in the omitted terms (the gravitational un-constant) means that $C U$ and the unconstant will always be correlated over time.

This point probably explains why the second, harder way of correcting for the relative-prices-matter effect in Rose-Van Wincoop yields such a different result from the country-dummy approach. Given all the structure imposed on their expenditure system, the they can actually generate data for the missing terms. When they do, the estimated Rose effect is again radically reduced. Doing some rough calculations on the numbers in the paper suggests the coefficient on the common currency dummy fell to 0.65 , or about one standard deviation.

\section{Pair dummies (time invariant)}

The second standard technique for redressing the gold medal problem is to include pair dummies. Of course this cannot work on cross-section data since the number of dummies equals the number of observations (at least with averaged bilateral 
trade). With panel data it is trivial to implement since it boils down to the classic fixed effect estimator (each bilateral flow is treated as a separate section). Using the theory to see what is going on with this, observe that:

$$
V_{o d}=\frac{\tau_{o d}^{1-\sigma}}{\Omega_{o} P_{d}^{1-\sigma}} Y_{o} E_{d} \Leftrightarrow \ln V_{o d, t}=(1-\sigma) \ln \tau_{o d, t}+\ln Y_{o} E_{d}-\ln \left(\Omega_{o, t} P_{o, t}^{1-\sigma}\right)
$$

Plainly, estimating the model with pair dummies will remove some of the gold medal bias that stems from the exclusion of the last term (the gravitational unconstant). However, as with country dummies, the time-series correlations between the omitted variable, namely $\ln \left(\Omega P^{1-\sigma}\right)$, and the included variables is not eliminated so some bias remains.

The point is made clearer by writing out the formula for the estimated coefficient:

$$
\hat{\beta}_{1}=\left(\begin{array}{c}
1 \\
-b_{1}(\sigma-1) \\
b_{2}(\sigma-1)
\end{array}\right)+\left(X_{1}^{\prime} X_{1}\right)^{-1}\left[\begin{array}{ll}
x y_{t} \cdot x_{21 t} & x y_{t} \cdot Z_{t} \\
d i s t \cdot x_{21 t} & d i s t \cdot Z_{t} \\
C U_{t} \cdot x_{21 t} & C U_{t} \cdot Z_{t}
\end{array}\right]\left(\begin{array}{c}
1 \\
b_{3}
\end{array}\right)
$$

We can think of the inclusion of pair dummies as a two step regression. First the left-hand side variable is regressed on the pair dummies and then the residuals from the first-stage regression are regressed on the three right-hand side variables, ry, dist and $C U$. The first stage will strip out any time-invariant pair influences, including all omitted determinants of bilateral trade are time-invariant.

If all the Z's - the omitted determinants of bilateral trade costs - are timeinvariant, then pair dummies will zero out the second column in the 3 by 2 matrix of biases. In most cases, however, ongoing trade liberalisation - on which the researcher does not have good data - implies that there will be a time-series component of the correlations in the second column even after the cross-section correlation has been stripped out. In the literature on the euro's Rose effect, this point has been well appreciated. For example, Berger and Nitsch (2005) and Bun and Klaassen (2004), find strong evidence of a time-varying pair effect that is omitted from the standard Rose regression. In the case of the euro, the source of the bias is probably the ongoing Single Market liberalisation that is proceeding at a somewhat different pace for each EU member due to lags in implementing the Single Market Directives (i.e. the liberalising rules agreed at the EU level) into national legislation. As for the size of the bias, Berger and Nitsch (2005) find that inclusion of a time trend as proxy of EU integration dramatically reduces the estimated Rose effect and makes it statistically insignificant. 
When it comes to first-column biases, i.e. biases stemming from correlations with $x_{21}$, we note that the pair dummy does at least as good a job of removing all crosssection correlation as does the nation dummy approach. The time-series correlation, however, remains equal for both the pair and nation dummy approaches.

In summary, time invariant pair dummies will eliminate part of the gold-medal bias. Specifically it will eliminate the cross-section component of the first-column and second-column biases. In this sense, pair dummies are superior to nation dummies in panel data. On the downside, the inclusion of pair dummies means that no time-invariant parameters such as distance elasticity can be estimated. Furthermore, pair dummies means that the coefficient of interest, e.g. the Rose effect coefficient, will be identified solely on the time variation in the policy variable. This means that pair dummies only work when there has been significant time variation in the policy whose impact one is trying to estimate.

\section{B. How important are the Gold, Silver and Bronze medal errors?}

We turn now to trying out the theory on a real data set. To be concrete, we focus on the question of the size of the euro's trade impact. The paper we take as our reference point is Micco, Stein and Ordoñez (2003), the source of the best known estimates of the euro's currency-union trade effect.

\section{Data}

In the subsequent section we suggest some procedures to improve the estimation of the Rose effect. Here, however, we start by using the theory to illustrate common mistakes taking as given the standard approach to gravity model implementation issues. This should be thought of as something of a thought experience; given the standard data choices, the theory can help us understand the importance of the various dummy approaches to estimating the gravity model. In the simplest gravity model, the data set consists of the dependent variable and three main right-hand side variables, economic mass, bilateral distance and the policy variable of interest. We start by discussing some of the issues and common practices for the dependent variable.

There are several sources for bilateral trade data. We use one that is convenient to access and widely available, the IMF's Direction of Trade Statistics (DOTS) data base. Given its very nature, bilateral trade is observed and reported by two nations, the importer and the exporter. For most nations, there are therefore four observations on bilateral trade. For example, French exports to Germany are reported as an export 
by the French and an import by the Germans. Likewise, German exports to France are recorded twice, as an export by Germany and an import by France. Many authors average all of these to get their one estimate of bilateral trade, although there is an old tradition in the gravity literature of using only import data on the grounds that nations spend more on measuring imports than exports (to avoid tariff fraud). Since 1993, this point is reversed for the EU since trade data is gathered from VAT statistics and here exporters get paid to announce exports (they get a VAT rebate) while they have an incentive to disguise imports.

The basic theory tells us that the gravity equation is essentially an expenditure equation. The natural specification is therefore to relate the value of bilateral exports to the value of the importing nation's expenditure - both measured in terms of the numeraire. However, it is common practice to use real GDP instead of GDP, as if the gravity equation were based on a demand equation instead of an expenditure equation. In fact some studies, such as Baxter and Kouparitsas (2006), do not bother reporting exactly which measure of GDP they use. As we shall see, however, the exact measure of GDP matters. The section below sticks with the common practice by using the product of real GDP for the trade partners, where real GDP means nominal GDP in national currency deflated by a national price index and then converted to US dollars at current exchange rates. The source is the IMF. Distance between nations is not a well defined concept. There are many efforts to improve measures of bilateral distance (see Head and Mayer 2000 for an example), but the simplest is the great circle distance between capitals. This is the most commonly used and so we follow the practice here. The 'variable of interest' in our regressions will be the pro-trade impact of common membership in the Eurozone. The dummy, EZ11, indicates that both partners use the euro. ${ }^{9}$ It is common practice to throw in a handful of variables that the author suspects may influence bilateral trade costs. The idea is to reduce the bias from omitted determinants of bilateral trade costs. Here we use a number of the most popular variables, namely adjacency (contig), landlocked (locked_i), and common official language (lang_off).

\section{Estimates of the size of the bronze and gold medal mistakes}

Table 2 shows the results of regressions on our dataset that is crafted to match that of Micco, Stein and Ordoñez (2003) in terms of country and year coverage.

\footnotetext{
${ }^{9}$ Note that all EU members are part of EMU (which stands for Economic and Monetary Union according to the Maastricht Treaty that launched the Eurozone), but only 12 (13 as of 2007) are members of the Eurozone (EZ); the distinction is similar to that of the ERM and the EMS.
} 
Table 2. Dummies and gold and bronze medal mistakes, panel estimation

\begin{tabular}{|c|c|c|c|c|c|c|}
\hline & $(1)$ & (2) & (3) & $(4)$ & $(5)$ & (6) \\
\hline Mistakes: & $\begin{array}{c}\text { Gold, Silver } \\
\& \text { Bronze }\end{array}$ & Gold \& Silver & $\begin{array}{l}\text { Partial Gold, } \\
\text { Silver \& Bronze }\end{array}$ & $\begin{array}{l}\text { Partial Gold } \\
\text { \& Silver }\end{array}$ & $\begin{array}{l}\text { Partial Gold, } \\
\text { Silver \& Bronze }\end{array}$ & $\begin{array}{l}\text { Partial Gold } \\
\text { \& Silver }\end{array}$ \\
\hline Estimator: & OLS & Time Only & Pair Only & Time \& Pair & Nation Only & Nation \& Time \\
\hline Eurozone dummy, EZ11 & 0.87 & 0.00 & 0.00 & 0.00 & 0.00 & 0.00 \\
\hline \multirow[t]{2}{*}{ Lry } & 0.77 & 0.77 & 0.37 & 1.13 & 0.27 & 1.18 \\
\hline & 0.00 & 0.00 & 0.00 & 0.00 & 0.00 & 0.00 \\
\hline $\mathrm{Eu}$ & 0.00 & 0.00 & 0.00 & 0.12 & 0.00 & 0.00 \\
\hline \multirow[t]{2}{*}{$\mathrm{Ld}$} & -0.76 & -0.76 & & & -0.86 & -0.86 \\
\hline & 0.00 & 0.00 & & & 0.00 & 0.00 \\
\hline \multirow[t]{2}{*}{ locked_o } & -0.34 & -0.34 & 2.81 & -3.03 & & \\
\hline & 0.00 & 0.00 & 0.00 & 0.00 & & \\
\hline locked_d & -0.12 & -0.11 & 2.80 & -0.13 & & \\
\hline lang_off & 0.00 & 0.00 & & & 0.00 & 0.00 \\
\hline \multirow[t]{2}{*}{ _cons } & 13.8 & -13.8 & -0.6 & -36.9 & 14.5 & -33.4 \\
\hline & 0 & 0 & 0.534 & 0 & 0 & 0 \\
\hline Number of observations & 2431 & 2431 & 2431 & 2431 & 2431 & 2431 \\
\hline $\mathrm{R}^{2}$ & 0.92 & 0.92 & 0.99 & 1.00 & 0.95 & 0.95 \\
\hline
\end{tabular}

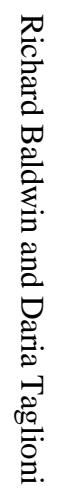

Notes: p-values under the point estimates. The nations in the sample are the EU15 plus the Australia, Canada, Switzerland, Iceland., Japan, Norway, New Zealand and the USA ,. The time period is 1992 to 2002 as in Micco, Stein and Ordoñez (2003). There are no zeros in this dataset since it involves only large nations. Definitions: EZ11=common use of euro, lry = product of real GDPs in US \$, eu=common membership in EU, locked_i indicates nation $\mathrm{i}$ is landlocked ( $\mathrm{i}=\mathrm{o}$ for origin, $\mathrm{i}=\mathrm{d}$ for destination), contig indicates the nations are geographically contiguous, lang_off indicates the pair shares an official langage, and _cons is the constant. 
The first column includes all three errors since the bilateral trade data is wrongly averaged (silver) and wrongly deflated (bronze) and the gravitational un-constant term is ignored (gold).

It is important to note that despite these errors, there is nothing overtly wrong with the estimates in the sense that it would fall well within most researcher's priors. The Rose effect is estimated to be very small ( 0.01 indicates about a $1 \%$ bilateral trade boost) and insignificantly different than zero (the p-value is 0.87 ). The economic mass variable, lry, has a reasonable if somewhat low point estimate of 0.77 , and distance, ld, has a fairly standard estimate for European data of -0.76; both are highly significant. EU membership is estimated to boost bilateral trade by about $20 \%$, which is a fairly common finding. The other bilateral trade cost controls have usual signs, magnitudes and p-values.

Time dummies only. Column two shows what happens when the time dummy only is included. This corrects the bronze medal mistake (incorrect deflation of bilateral trade). We see that this correction implies little changes for most coefficients but it implies a big jump in the size and significance of the 'variable of interest.' In other words, the bronze mistake in isolation would reverse the policy conclusion from the gravity equation regression. When one wrongly deflates bilateral trade - as is common practice - one finds that the euro had no effect on trade; if one offsets the error with time dummies - as is common practice - one finds that the euro had a strong pro-trade effect, so strong that it is estimated to be equal to the effect of EU membership. In fact when we re-do the column 2 estimation using trade data that has not been wrongly deflated, the point estimates with time dummies are exactly those in column $2 .^{10}$

Pair and Time dummies. Probably the most common estimator involves OLS with both time and pair dummies, for example this is preferred regression of Micco, Stein and Ordoñez (2003); this is shown in column four. As argued above, the time dummies eliminate the bronze mistake and the pair dummies reduce the severity of the gold-medal mistake by eliminating the cross-section correlation between the omitted and P terms and the included variables. As argued in section 3.2 , the cross-section correlation is likely to be positive so including the pair dummies reduces the estimated impact of the euro; comparing column 2 to column 4 , we see that indeed it falls from 0.17 to 0.10 , with both highly significant. The point estimates on the economic mass variable also appears more in line with

\footnotetext{
${ }^{10}$ The result, not reported in the table, uses $1 v \_$avg instead of lvus_avg as the dependent variable (see Table 1) but otherwise uses the same data and specification.
} 
theory at 1.13 instead of 0.77 . Again we argued in section 3.2 that underestimation of this coefficient should be expected since deflating the GDP by the GDP price deflator is a measurement error (or a noisy version) of the correct estimator, i.e. nominal GDP deflated by the gravitational un-constant term 'od, if the theory is right. On the downside, the coefficient on EU membership drops enormously and becomes insignificant at the $10 \%$ level. The reason is that the data period includes only three switches in EU status (Austria, Finland and Sweden joined in 1994) and the pair dummy wipes out all the cross-section correlation between membership and bilateral trade. This, of course, is the downside of using pair dummies to estimate the impact of policies that have not varied much over time.

A quick glance at column 3 re-confirms the importance of the bronze medal mistake. It displays the results with pair dummies when the incorrect deflation of trade is not offset with time dummies. The results seem to be all wrong; the economic mass coefficient is far too low and the landlocked controls have the wrong sign. One does not often see such results reported and it may explain why authors almost universally include time dummies in panel gravity regressions despite the lack of clear theoretical motivation.

Nation and Time dummies. Nation dummies are the next most common correction for the gold-medal mistake (i.e. failure to account for what Anderson and Van Wincoop 2001 referred to as the multilateral trade resistance term, what we have been calling the gravitational un-constant). This estimator is shown in column six (when time dummies are also included). The column six results have one big advantage over those of column four (pair and time) and one big disadvantage. The disadvantage is that the country dummies do not control for idiosyncratic bilateral trade factors, as argued in section 4.1.1. While the omitted variable biases is always an issue, in the case at hand it operates with particular force due to the likelihood of reverse causality, i.e. nations adopted the common currency because they trade a lot for innumerable reasons on which the econometrician has no data. That is, there are likely to be many excluded pro-trade variables that are correlated with common Eurozone membership - after all, the decision to adopt the euro was endogenous and trade integration with the main euro-adopters, Germany and France, was one key element in the decision of nations. The main point of the disadvantage is that the coefficient on the 'variable of interest' EZ11 is almost surely biased upward. The advantage is that the EU membership variable fits better with priors that EU membership should have a big impact on trade flows.

Another quick glance at the preceding column, column 5, reinforces the point 
about the bronze mistake. When only nation dummies are included, the point estimates on economic mass seem all wrong.

\section{Estimates of the size of the silver medal mistake}

Next we turn to estimating the size of the silver-medal on our particular dataset. For reasons that are not always made clear, many authors choose to work with trade that is averaged bilaterally instead of direction-specific trade as the theory would suggest. The theory asserts that the gravity models holds for each and every uni-directional trade flow, so averaging two trade flows should not cause problems if the averaging is done correctly. Because the gravity equation is basically a modified CES expenditure function, it is naturally multiplicative. The averaging of two trade flows should thus be geometric (i.e. the sum of the logs), but most authors take the arithmetic average (log of the sums).

As argued in section 3.3, the empirical relevance of the mistake depends upon the correlation between the averaging error and the variable of interest, in our case, the pro-trade effect of the euro. Table 3 reestimates our basic model using the three main estimators, OLS, pair and time dummies, and nation and time dummies with and without the silver medal error. Quite specifically, in columns 1, 3 and 5, the dependent variable is $1 v \_a v g$ (which involves the log of the sum of uni-directional flows), while for columns 2, 4 and 6 the dependent variable is $1 v \_$prd (which involves the sum of the logs). In all cases, we have avoided the bronze medal mistake by not deflating the value of trade by the US price index (the time dummies absorb the correct deflation factors).

To understand the results, note that column 1 displays the gold and silver mistakes. That is, the and $\mathrm{P}$ terms are omitted and not addressed with dummies, and the dependent variable involves the arithmetic average. Column 2 displays the gold medal mistake only, since it uses the correctly averaged trade variable. Comparing the two, we see that the silver medal mistake leads to a serious overestimate of the pro-trade impact of the euro. With the mistake, the euro is estimated to boost bilateral trade by about $10 \%$ and the effect is highly significant. When the silver mistake is corrected, we get an entirely different policy conclusion - the euro is estimated to have a small and statistically insignificant impact on trade. This is due to the fact that bilateral trade is not balanced in our data set and that the imbalance is, on average, higher among Eurozone nations. The other main variables are not significantly affected by the silver medal mistake.

The same conclusion flows from the with-versus-without comparison for the other 
Table 3. The silver medal mistake, panel estimation

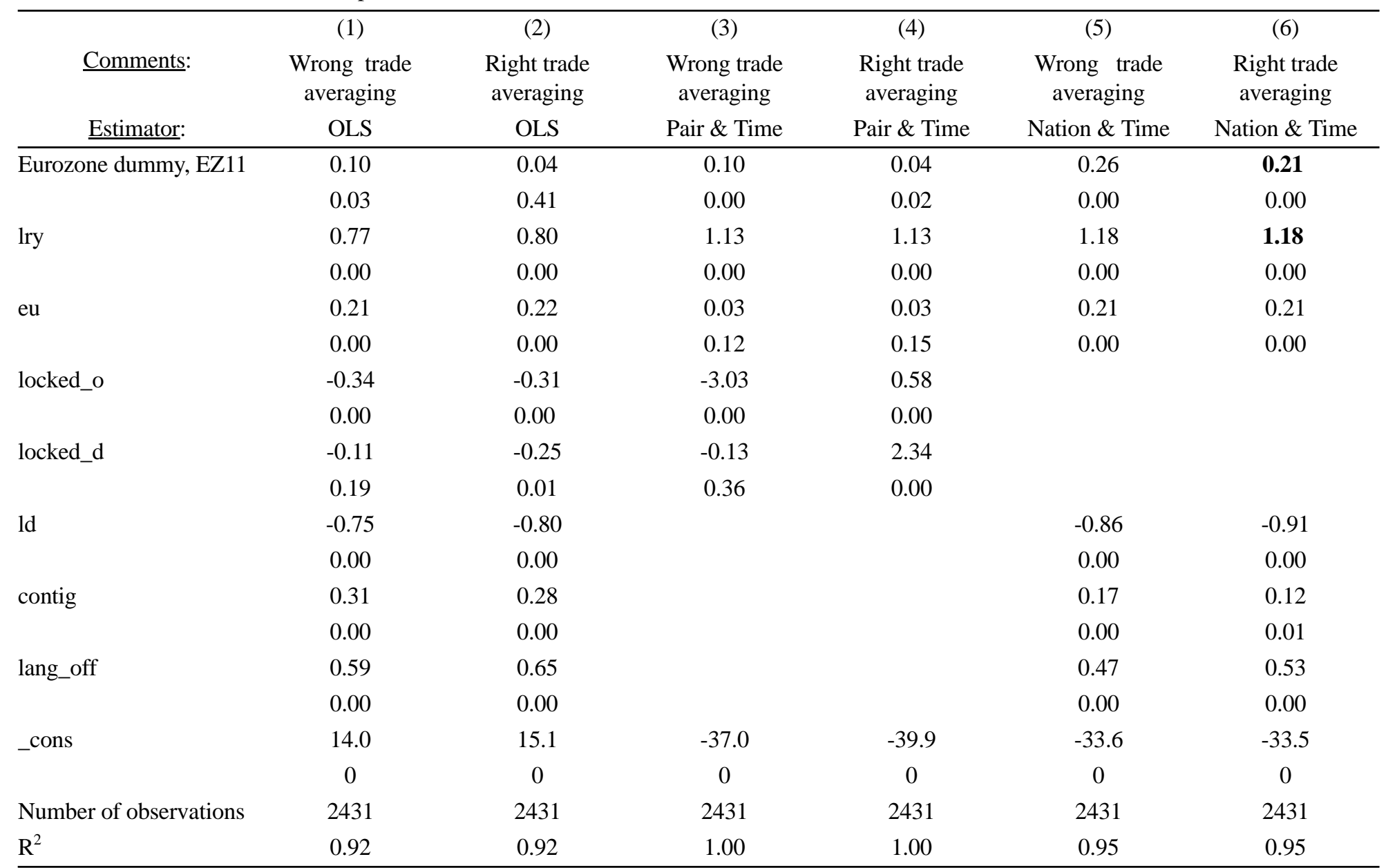

Notes: p-values under the point estimates. See Table 2 for other details. The left-hand side variable is the log of nominal trade averaged arithmetically (wrong) and geometrically (right). 
two estimators. Comparing column 3 and 4, we see that the silver medal mistake lowers the estimate of the Rose effect a great deal, from about $10 \%$ to about $4 \%$ (this is more than four standard deviations). It is important to note, that the pair dummies already control for all other time-invariant unobservable factors affecting bilateral trade. Thus it is really the time-series correlation between the averaging error and the EZ dummy which is causing the bias. The large jump in the landlocked variable may indicate a spurious correlation in the data.

For the nation-dummy estimator with time dummies, we see that the silver medal mistake also produces an upward basis in the size of the Rose effect, but the magnitude of the mistake is less severe.

\section{Why not test if bilateral trade is balanced?}

The results in Table 3 suggest that the incorrect averaging of bilateral trade can be important. There is, however, a more direct way of looking at the importance of the silver error. By definition of the problem, the researcher can test whether bilateral trade is balanced. If trade is bilaterally balanced then there is no harm in taking the log of the sums instead of the sum of the logs (right way). There are several ways to test the trade-balance hypothesis, we focus on the relative imbalance defined as $b_{i j t}=\left|X_{i j}-M_{i j t}\right| /\left|X_{i j}+M_{i j}\right|$, where the subscripts have the obvious interpretations and numerator and denominator are taken in absolute values. In our dataset - crafted to match that of Micco, Stein and Ordoñez (2003) in terms of country and year coverage - we tested for balanced trade by the relative

Figure 1. Distribution of bilateral trade imbalance.

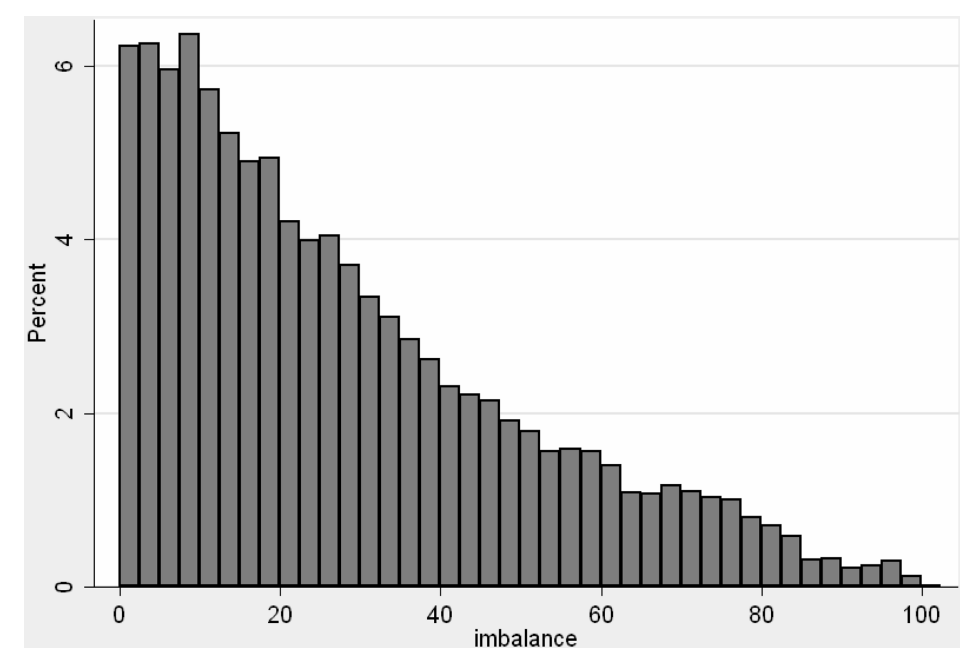


measure bi. A simple test of the hypothesis that $b=0$ for all flows is strongly. Figure 1 shows the complete histogram in percentage terms. The $\mathrm{x}$-axis shows the size of the trade imbalance as measured in $b_{i j t}{ }^{--}$and transformed in percentage terms - while the y-axis shows what percentage of individual bilateral trade flows in the sample report a particular trade imbalance. From the histogram, it appears that only $6 \%$ of overall trade has an imbalance close to zero, while for approximately one-third of our bilateral trade flows imports are at least double the exports or viceversa.

Further investigation shows that the trade imbalance problem is not randomly distributed by nation. When it comes to the bilateral flows in our data, Greece imports about 60 percent more of than it exports while Ireland exports about 40 percent more than it imports. More generally, large countries tend to have a more balanced trade. Given the nation-specific variation for the Rose effect in Micco, Stein and Ordoñez (2003) and other studies, this finding is fairly important. It suggests that at least some of the variation in Rose effects is due to varying severity of the silver medal mistake.

\section{Some Suggested Improvements}

We turn now to considering some approaches that may reduce the biases discussed above.

\section{Nominal trade and GDP data with time dummies}

Since the gravity model is based on an expenditure equation, it is natural to use the value of spending by nation-d on goods from nation-o as well as to use the value of total expenditure in nation-d with both - of course - measured in terms of a common numeraire. These choices imply that we should also use the value of total output of nation-o in the gravity equations, see (5). The immediate problem that this choice raises is the choice of numeraire. Since the value of GDPs and trade are in current dollars each year's data uses a different numeraire. A common solution to this is to use real GDP (as we did above) which is measured in, say, 2000 dollars and so automatically rendered into a common numeraire. This solution, however, requires that the trade figures also be deflated back to 2000 dollars. Since few nations have good price indices for bilateral trade flows, the common solution has been to deflate the trade figures back to a common year using, e.g. a US price index, as was done above. As we saw, this procedure can introduce important 
biases. Flam and Nordstrom (2003) address this problem by using the exporting nation's producer price index as a proxy for the bilateral export price index and using real GDP figures; they also always include time dummies.

We suggest that the econometrician can estimate the proper conversion factor between US dollars in different years by including time dummies. To illustrate the basic point consider what the basic gravity equation would look like if everything were measured in current US dollars and multiplied by a conversion factor $e_{t, 95}$ that converts the year-t dollars to base-year dollars, say 1995. If the elasticity of substitution, $\sigma$, is the same for all nations, then the e's will just cancel out (the equation is homogenous of degree one); if it is not, then we need to include year dummies to control for the residual conversion factors.

$$
e_{t, 95} V_{o d}=\tau_{o d}^{1-\sigma}\left(\frac{\left(e_{t, 95} Y_{o}\right)\left(e_{t, 95} E_{d}\right)}{\sum_{i=1}^{R}\left(\tau_{o i}^{1-\sigma} \frac{e_{t, 95} E_{i}}{e_{t, 95}^{1-\sigma} P_{i}^{1-\sigma}}\right)\left(\sum_{k=1}^{R} n_{k} e_{t, 95}^{1-\sigma} p_{k d}^{1-\sigma}\right)}\right)
$$

Plainly the time dummies will pick up other idiosyncratic year-specific shocks, so the conversion factors are not easily identified from the estimated time dummies.

\section{Time-varying country dummies with pair dummies}

As noted in Section 4.1.1, the inclusion of country dummies removes the crosssection correlation between the unobservable $\Omega P^{1-\sigma}$ term and the included variables and thus reduces that gold-medal bias. The time-invariant country dummies, however, do not remove the time series correlation. Since gravity models are frequently estimated over a period in which the determinants of bilateral trade cost are timevarying, these determinants are also in the unobservable $\Omega P^{1-\sigma}$ term and this timeseries correlation is a source of bias.

One possible correction is to include time-varying country dummies. This involves a lot of dummies, viz. 2NT for uni-direction trade data, where $\mathrm{N}$ is the number of nations and $\mathrm{T}$ is the number of years. However, with a square panel we will have $2 \mathrm{~N}(\mathrm{~N}-1) \mathrm{T}$ observations. If $\mathrm{T}$ and $\mathrm{N}$ are large, there will be many degrees of freedom, even with $\mathrm{T}$ time dummies. Note that the alternative of using time-varying pair dummies will make it impossible to estimate factors that affect bilateral trade costs even if they are time varying. Since most gravity models are aimed at identify trade barriers for various kinds, the time-varying pair dummy approach will rarely be useful. 
The time-varying country dummies do not remove the bias stemming from the correlation between included determinants of bilateral trade (like the Eurozone dummy) and the determinants that are unobservable to the econometrician. To this end, it is useful to included time-invariant pair dummies.

\section{Estimates}

To try out the suggestions of using nominal trade and GDP and time-varying nation-role dummies, we reestimate our standard gravity model on the same set of nations and years as in the previous tables. Specifically, the dependent variable is un-deflated uni-directional trade. On right-hand side, we use the product of current GDPs measured in dollars as the economic mass variable and we include all the usual controls when possible. The results are shown in Table 4. Our preferred regression - with time-varying nation and pair dummies - is in the right-most column, but we discuss the other columns to begin with.

The first column, shows the results when OLS is used. This regression features the gold-medal mistake (correlation between $\Omega P^{1-\sigma}$ and the Eurozone dummy), so the point estimate of the Eurozone's pro-trade effect is upward biased. Including only a time dummy does little to change the results. Including pair dummies along with time dummy lowers the Rose effect substantially. Including nation dummies or nation-role dummies raises the EZ point estimate. Although this is somewhat puzzling (since nation dummies should eliminate the cross-section part of the goldmedal bias), we saw the same thing in Table 2. Note that both in Table 4 and Table 2 the nation and time dummy point estimates on GDP drop significantly, so we may be seeing a bias in one coefficient spilling over into another. One feature of the results that supports this interpretation is the fact that the EU dummy also jumps up compared to the OLS regression. The nation and time, and the nationrole and time dummy regressions yield very similar results.

Moving on to our new estimators, the sixth column shows the estimates when we include time varying nation dummies. These dummies, which also absorb the time dummies, should completely eliminate the bias stemming from the gold-medal error, i.e. the omission of term that Anderson and Van Wincoop (2003) called multilateral trade resistance. It should also eliminate any problems arising from the incorrect deflation of trade and GDP figures. Looking at the point estimates in isolation, the estimator seems to do a fine job of eliminating biases. All variables are significant at any reasonable level of significant and have the right sign and roughly plausible magnitudes. The point estimate on the economic mass variable is quite close to unity 
Table 4. Gravity estimates with uni-directional nominal trade and GDPs

\begin{tabular}{|c|c|c|c|c|c|c|c|}
\hline & OLS & Time only & Pair \& Time & Nation \& Time & $\begin{array}{c}\text { Importer, } \\
\text { Exporter \& Time }\end{array}$ & $\begin{array}{c}\text { Time-varying } \\
\text { Nation }\end{array}$ & $\begin{array}{l}\text { Time varying } \\
\text { Nation and Pair }\end{array}$ \\
\hline$\overline{\text { EZ11 }}$ & 0.17 & 0.13 & 0.09 & 0.24 & 0.26 & 0.34 & -0.09 \\
\hline (Rose effect) & 0.00 & 0.00 & 0.00 & 0.00 & 0.00 & 0.00 & 0.00 \\
\hline \multirow[t]{2}{*}{ ly } & 0.81 & 0.81 & 0.57 & 0.65 & 0.70 & 0.98 & 0.94 \\
\hline & 0.00 & 0.00 & 0.00 & 0.00 & 0.00 & 0.00 & 0.00 \\
\hline \multirow[t]{2}{*}{ EU } & 0.14 & 0.14 & 0.06 & 0.20 & 0.21 & 0.22 & 0.04 \\
\hline & 0.00 & 0.00 & 0.00 & 0.00 & 0.00 & 0.00 & 0.23 \\
\hline \multirow[t]{2}{*}{ locked_o } & -0.26 & -0.25 & 5.17 & & & & \\
\hline & 0.00 & 0.00 & 0.00 & & & & \\
\hline \multirow[t]{2}{*}{ locked_d } & -0.49 & -0.49 & -5.87 & & & & \\
\hline & 0.00 & 0.00 & 0.00 & & & & \\
\hline \multirow[t]{2}{*}{ ld } & -0.86 & -0.86 & & -0.93 & -0.93 & -0.93 & \\
\hline & 0.00 & 0.00 & & 0.00 & 0.00 & 0.00 & \\
\hline \multirow[t]{2}{*}{ contig } & 0.17 & 0.17 & & 0.11 & 0.11 & 0.11 & \\
\hline & 0.00 & 0.00 & & 0.02 & 0.01 & 0.02 & \\
\hline \multirow[t]{2}{*}{ lang_off } & 0.68 & 0.67 & & $\mathbf{0 . 5 3}$ & 0.53 & 0.53 & \\
\hline & 0.00 & 0.00 & & 0.00 & 0.00 & 0.00 & \\
\hline \multirow[t]{2}{*}{ _cons } & -15.50 & -15.56 & -7.23 & -5.75 & -8.18 & -23.58 & -30.77 \\
\hline & 0.00 & 0.00 & 0.00 & 0.19 & 0.00 & 0.00 & 0.00 \\
\hline Observations & 4837 & 4837 & 4837 & 4837 & 4837 & 4837 & 4837 \\
\hline $\mathrm{R}^{2}$ & 0.88 & 0.88 & 0.99 & 0.91 & 0.93 & 0.91 & 0.99 \\
\hline
\end{tabular}


as predicted by the simple theory (and tightly estimated). The point estimate on EU membership has a plausible size of 0.22 implying that intra-EU trade flows are boosted by $24.6 \%{ }^{11}$ The other standard explanatory variable, distance, is estimated at -0.93 which is quite close to the traditional prior of -1.0 (although this is not a theoretical prediction). The one point estimate that seems somewhat out of line is the Eurozone impact. At 0.34 , or $40 \%$, the figure seems a bit high; it is definitely much higher than the consensus estimate of 5 to 15 percent. This outcome, however, is not unexpected due to the second bias discussed in Section 3.2 - the correlation between the Eurozone dummy and unobservable pro-trade factors.

The final column corrects for this bias by including time-invariant pair dummies in addition to the time-varying nation dummies. This has a radical impact on the Rose effect estimate, turning it negative and statistically significant. This result, however, is somewhat suspect since the pair dummies also greatly reduce the estimated impact of EU members and render it statistically insignificant. One interpretation of these results turns on the fact that the pair dummies wipe out information in the cross-section variation, so all identification comes from time variation in the variables. Since EU membership varied very little during our period (Austria, Finland and Sweden became members in 1995), it is possible that the regression is having difficulty in distinguishing between the pair dummies which are absolutely time-invariant and the EU membership which is almost timeinvariant. As always, the pair dummies absorb all time-invariant determinants of bilateral trade costs such as distance and common language.

One solution to the high standard errors is to add data. In Table 5, we use data back to 1980 and this more than doubles the number of observations. The results are quite good. The Eurozone effect is negative but insignificantly different to zero, while the EU dummy takes on a plausible and significant magnitude while the log of the product of the GDP is estimated at 0.74 . While this is somewhat low, it is not

Table 5. Gravity model estimated with time-varying nation \& pair dummies, 1980-2004

\begin{tabular}{lcccc}
\hline & EZ11 & ly & EU & _cons \\
\hline Coefficient & -0.02 & 0.74 & 0.24 & -19.56 \\
Standard Error & 0.03 & 0.03 & 0.02 & 1.4 \\
p-value & 0.38 & 0.00 & 0.00 & 0.00 \\
$\mathrm{R}^{2}=0.98, \mathrm{~N}=10,788$ & & & & \\
\hline
\end{tabular}

Note: See text for details of the regression and variable definitions.

\footnotetext{
${ }^{11}$ The formula is $\exp$ (coefficient)- 1 .
} 
out of the range of commonly observed values and given the measurement errors this proxy involves we view it as plausible.

\section{Concluding Remarks}

The gravity model is a very useful and popular tool in international empirical economics. This paper discusses the straightforward theory behind the equation and uses that theory to illustrate several mistakes that are common in the literature. There are surely many more theoretical and empirically advances to be made when it comes to the gravity equation. Of the many issues not addressed in this paper, the most important and interesting concerns the proper handling of zero trade flows, and the issues surrounding the estimation of the gravity model on disaggregated data.

\section{Acknowledgments}

This paper reflects views of the authors that do not necessarily correspond with those of the ECB nor imply the expression of any opinion whatsoever on the part of the ECB

Received 27 February 2007, Accepted 27 March 2007

\section{References}

Alho, K. (2002) "The Impact of Regionalism on Trade in Europe," Royal Economic Society Annual Conference 2003 3, Royal Economic Society.

Anderson, James (1979) "The theoretical foundation for the gravity equation," American Economic Review 69, 106-116.

Anderton, Robert, B. Baltagi, F. Skudelny and N. Sousa (2002) "Intra- and Extra-Euro Area Import Demand for Manufactures" ECB working paper no. 532.

Balassa, Bela (1965) "Trade Liberalisation and Revealed Comparative Advantage" The Manchester School of Economics and Social Studies, no.33, May.

Barr, David, Francis Breedon and David Miles (2003) "Life on the Outside" Economic Policy, 573-613.

Barr, David, Francis Breedon and David Miles (2003) "Life on the outside: economic conditions and prospects outside Euroland," Imperial College, University of London, manuscript.

Baxter, Marianne and Michael Kouparitsas (2006) "What determines bilateral trade flows?," NBER Working Paper 12188. 
Berger, Helge and Nitsch, Volker (2005) "Zooming Out: The Trade Effect of the Euro in Perspective" CESifo Working Paper No. 1435.

Bergstrand, J. (1985) "The Gravity Equation in International Trade: Some Microeconomic Foundations and Empirical Evidence," Review of Economics and Statistics, 1985, 67:3, August, pp. 474-81.

Bowen, H. P., E. E. Leamer, and L. Sveikauskas (1987) Multicountry, Multifactor Tests of the Factor Abundance Theory. American Economic Review 77 (December): 791809.

Bun, Maurice and Franc Klaassen (2004) "The euro effect on trade is not as large as commonly thought" http://www1.fee.uva.nl/pp/klaassen/.

Bun, Maurice J. G. and Franc J. G. M. Klaassen (2002) "Has the Euro Increased Trade?", Tinbergen Institute Discussion Paper, TI 2002-108/2.

Combes, P-P., Lafourcade M. and T. Mayer (2005) "The Trade Creating Effects of Business and Social Networks: Evidence from France", Journal of International Economics, 66(1): 1-29. De Nardis, Sergio and Claudio Vicarelli (2003) "Currency Unions and Trade: The Special Case of EMU”, World Review of Economics, 139 (4): 625-649.

De Sousa, Lucio V. (2002) "Trade Effects of Monetary Integration in Large, Mature Economies", A Primer on European Monetary Union, Kiel Working Paper No. 1137. Deardorff, Alan, 1998, "Determinants of bilateral trade: does gravity work in a neoclassical world?," in Jeffrey.

Frankel (ed.), The regionalization of the world economy, University of Chicago Press.

Eaton, Jonathan and Samuel Kortum (2002) "Technology, Geography, and Trade", Econometrica 70(5): 1741-1779 (September).

Engel, Charles and John H. Rogers (2004) "European Product Market Integration after the Euro", forthcoming European Policy. European Commission, 2000, REPORT FROM THE COMMISSION TO THE COUNCIL AND THE EUROPEAN PARLIAMENT, COM(2000) 28 final.

Feenstra, Robert. (2003) Advanced International Trade. Princeton University Press, Princeton, New Jersey.

Flam, Harry, and Hakan Nordstrom (2003) "Trade Volume Effects of the Euro: Aggregate and Sector Estimates", Institute for International Economic Studies unpublished. Frankel, Jeffrey A. (1997) Regional Trading Blocs in the World Economic System. Institute for Internal Economics, Washington, D.C. Glick, Reuven and Andrew Rose (2002) "Does a Currency Union Affect Trade? The Time Series Evidence", European Economic Review 46-6, 1125-1151.

Gomes, T, Chris Graham, John Helliwell, Takashi Kano, John Murray, Larry Schembri (2004) "The Euro and Trade: Is there a Positive Effect?" pdf file of a preliminary and incomplete draft, not for quotation without permission.

Hamilton, C. and Winters, A. (1992) "Opening up international trade with Eastern Europe," Economic Policy.

Harrigan, James (1996) "Openness to trade in manufactures in the OECD," Journal of 
International Economics, Elsevier, vol. 40(1-2), pages 23-39, February. Head, K. and T. Mayer (2000) "Non-Europe : The Magnitude and Causes of Market Fragmentation in the EU", Weltwirtschaftliches Archiv, 136(2): 285-314.

Helpman, Elhanan and Paul Krugman (1985) Market structure and foreign trade, MIT Press.

Hummels, David, Jun Ishii and Kei-Mu Yi (2001) "The nature and growth of vertical specialization in world trade," Journal of International Economics 54, 75-96.

James E. Anderson and Eric van Wincoop (2001) "Gravity with Gravitas: A Solution to the Border Puzzle," NBER Working Papers 8079.

James E. Anderson and Eric van Wincoop (2003) "Gravity with Gravitas: A Solution to the Border Puzzle," American Economic Review, American Economic Association, vol. 93(1), pages 170-192, March. Journal of Political Economy 111, 52-102.

Kenen, Peter B. (2002) "Currency Unions and Trade : Variations on Themes by Rose and Persson" Reserve Bank of New Zealand Discussion Paper 2002/08. Leamer, E. E. 1980. The Leontief Paradox Reconsidered. Journal of Political Economy 88 (June), 495-503.

Leamer, E. E. (1984) Sources of International Comparative Advantage. Cambridge, MIT Press.

Learmer, E. (1974). "The commodity composition of international trade in manufactures: An empirical analysis," Oxford Economic Papers, 26, pp 350-374.

Learmer, E. and R. Stern (1970) Quantitative international economics, Allyn and Bacon, Boston.

Linnemmann, Hans (1966) An Econometric Study of International Trade Flows, NorthHolland, Amsterdam.

Markusen, and Venables, Anthony (2000) "The General Theory of Inter-Industry-, IntraIndustry-, and Multinational Trade", Journal of International Economics 52, 209-234.

McCallum, John (1995) "National Borders Matter: Canada-U.S. Regional Trade Patterns." American Economic Review, June, 85 (3), pp. 615-23.

Melitz, Jacques (2001) “Geography, Trade and Currency Union”, CEPR Discussion Paper, No. 2987.

Micco, Alejandro, Ernesto Stein and Guillermo Ordoñez (2003) "The currency union effect on trade: early evidence from EMU," http://www.economic $\neg$ policy.org/paneldrafts.asp.

Micco, Alejandro, Ernesto Stein, Guillermo Ordonez (2003) "The Currency Union Effect on Trade: Early Evidence From EMU”, Economic Policy, 316-356.

Pakko, Michael R. and Howard J. Wall (2001) "Reconsidering the Trade-Creating Effects of a Currency Union", Federal Reserve Board of St. Louis Review, 83-5, 37-45.

Persson, Torsten (2001) "Currency Unions and Trade: How Large is the Treatment Effect?", Economic Policy 33, 435-448.

Piscitelli, L. (2003) mimeo, available from UK Treasury.

Poyhonen, Pentti (1963) "A tentative model for the volume of trade between countries," Weltwirtschaftliches Archiv, 90, pp 93-99.

Poyhonen, Pentti (1963a) “A Tentative Model for the Volume of Trade Between 
Countries", Welwirtschaftliches Archiv, 90 (1): 93-99.

Poyhonen, Pentti (1963b) "Toward a General Theory of International Trade", Ekonomiska Samfundets Tidskrift, 16(2): 69-78.

Rose, Andrew K. (2000) "One Money, One Market: Estimating the Effect of Common Currencies on Trade", Economic Policy 30, 9-45.

Rose, Andrew K. and E. van Wincoop (2001) "National Money as a Barrier to Trade: The Real Case for Monetary Union", American Economic Review 91-2, 386-390.

Rose, Andrew K. and Eric van Wincoop (2000) "National money as a barrier to international trade: the real case for currency union," http://faculty.haas.berkeley.edu/ arose/

Rose, Andrew K. (2000) "One money, one market: the effect of currency unions on trade," Economic Policy 30, 7-46.

Rose, Andrew K. (2001) "Currency unions and trade: the effect is large," Economic Policy $33,449-461$.

Simon J. Evenett and Wolfgang Keller (2002) "On Theories Explaining the Success of the Gravity Equation," Journal of Political Economy, University of Chicago Press, vol. 110(2), pages 281-316.

April. Tenreyro, S. (2001) "On the Causes and Consequences of Currency Unions" Harvard University mimeo.

Tenreyro, Silvana and Robert J. Barro (2003) "Economic effects of currency unions," NBER Working Paper 9435.

Tinbergen, Jan (1962) Shaping the world economy: Suggestions for an international economics policy, The Twentieth Century Fund, New York.

Wang and Winters (1991) "The Trading Potential of Eastern Europe", CEPR Discussion Paper 610.

Westerlund, Joakim and Fredrik Wilhelmsson (2006). "Estimating the gravity model without gravity using panel data," www.nek.lu.se/nekfwi/Estimating\%20the\%20gravity $\% 20$ model.pdf.

Wooldridge, Jeffrey M. (2002) Econometric Analysis of Cross Section and Panel Data. MIT Press.

Yi, Kei-Mu (2003) "Can vertical specialization explain the growth of world trade?" 